\title{
The American Kinesiology Association Core Content for Kinesiology Programs: From Concept to Curriculum
}

\author{
Wojtek Chodzko-Zajko, Erica M. Taylor, and T. Gilmour Reeve
}

\begin{abstract}
The American Kinesiology Association identified the essential core content for undergraduate kinesiology-based academic programs. The core includes 4 content elements: physical activity in health, wellness, and quality of life; scientific foundations of physical activity; cultural, historical, and philosophical dimensions of physical activity; and the practice of physical activity. This article, expanding on the development of the core, describes the 4 elements in more detail, suggests methods for assessing student learning outcomes for the core content, and provides examples of the inclusion of the core in undergraduate curricula. Finally, a case study is presented that addresses how a department revised its kinesiology curriculum using the core elements to refocus its undergraduate degree program.
\end{abstract}

Keywords: kinesiology curriculum, student learning outcomes assessment, AKA

The American Kinesiology Association (AKA), established in 2007, promotes kinesiology as a unified field of study focused on advancing our discipline and its many career opportunities (Morrow \& Thomas, 2010). The AKA has become the leading organization working to define kinesiology as the discipline focused on the study of physical activity. It advocates for kinesiology as the appropriate designation of the academic discipline and works with kinesiology administrators to enhance the quality of our academic units and our undergraduate and graduate degree programs. The AKA offers leadership training through annual workshops and now through a mentor-based Leadership Institute.

As a unified field of study, it is important that kinesiology clearly articulate the common knowledge base that serves as the foundation for undergraduate degree programs in the field, regardless of any additional specializations that may be addressed in a particular program. In 2009, the AKA convened a meeting of kinesiology administrators and faculty to define the core content to be included in undergraduate degree programs focused on the study of physical activity. A common core for kinesiology would represent the essential knowledge, skills, and abilities that every undergraduate kinesiology student would have (Lawson, 2010).

Christina (2009) prepared a summary report of the 2009 workshop, detailing the discussions and issues that were addressed and resolved as the core concept emerged. Over the next 10 years, the AKA continued to promote the concept of a core content for kinesiology. The core content has been adopted by academic departments, and expected student learning outcomes have been developed to allow for assessment of core knowledge development among our undergraduate students.

This article documents the process used to formulate the core content, describes the core knowledge for kinesiology, chronicles the steps taken to encourage adoption of the core content (also see Chodzko-Zajko, 2014), provides guidance for developing

Chodzko-Zajko is with the Graduate College, University of Illinois at UrbanaChampaign, Champaign, IL. Taylor is with the Dept. of Public and Allied Health Sciences, Delaware State University, Dover, DE. Reeve is with the American Kinesiology Association, Champaign, IL. Chodzko-Zajko (Wojtek@illinois.edu is corresponding author. assessments of student learning outcomes for kinesiology degree programs that may vary considerably in purpose and scope, and reviews examples of how academic departments have included the core content in their programs. One specific example is provided of a department that shifted its undergraduate degree programs to a single degree program in kinesiology using the core content to justify its curriculum changes. Some of the material included in this article was previously shared in a different form with the academic community in a 2014 Quest publication (Chodzko-Zajko, 2014).

The AKA's position is that agreeing on a core content for kinesiology is not the same thing as mandating that all departments require a specific set of core courses. How the core content is organized and delivered will differ among kinesiology programs across the nation (Newell, 2007). Also, a common core content is not an accreditation standard (see Templin \& Blankenship, 2007, for a discussion of accreditation issues for kinesiology programs). Many academic disciplines have core knowledge bases without being discipline-accredited programs. The AKA strongly supports the concept of local responsibility for the academic curriculum. It is not likely that that all kinesiologists or kinesiology departments will achieve consensus with regard to how the undergraduate curriculum should be constructed and delivered. Indeed, several recent papers have expanded on the AKA core curriculum to provide an alternative perspective with respect to how the practice of physical activity is described in the AKA core (Johnson \& Twietmeyer, 2018; Twietmeyer, 2018). Such a scholarly exchange of ideas and perspectives around what should be in the kinesiology core is both appropriate and desirable. Ultimately, it is the faculty in each kinesiology department that are responsible for determining how the curriculum is structured and delivered. The AKA core content offers a starting point for such discussions and a framework for ensuring that all students graduating with a kinesiology degree or with a specialization in one of the kinesiology fields of study share a common knowledge base.

\section{Defining the Kinesiology Core Content}

As noted previously, the purpose of 2009 AKA Workshop was to reexamine the current academic content and if possible to identify an undergraduate core in kinesiology. This workshop followed the 
2006 meeting of the American Academy of Kinesiology and Physical Education (now the National Academy for Kinesiology, NAK) that considered essential academic core content for kinesiology (Reeve, 2007). After presentations and discussions among the AKA 2009 Workshop participants, four core content elements were identified that should be included in every kinesiology undergraduate degree program. The following statement was adopted by the AKA (Christina, 2009).

\section{Proposed Undergraduate Core of Kinesiology}

The AKA believes that undergraduate majors in kinesiology should share a common core of knowledge. The common core establishes broad knowledge categories that can be used as a guide by faculty in kinesiology to examine and refine current educational expectations, policies, and practices.

The undergraduate degree in kinesiology includes principles and experiences focused on physical activity across the life span. These include

- Physical activity in health, wellness, and quality of life

- Scientific foundations of physical activity

- Cultural, historical, and philosophical dimensions of physical activity

- The practice of physical activity

\section{Physical Activity in Health, Wellness, and Quality of Life}

There is a growing appreciation for the importance of regular physical activity as an integral component of a healthy lifestyle. Over the past 20-30 years, a substantial body of evidence has accumulated regarding the benefits that accrue to people of all ages who participate in regular physical activity (Ainsworth \& Hooker, 2015). These advances in our understanding of the relationship between physical activity participation and health have important implications for students of kinesiology. Whether kinesiology graduates pursue employment opportunities immediately after completing their undergraduate education or after the completion of postbaccalaureate educational opportunities in kinesiology or other health-related fields, all graduates serve as academic or community experts on health and active lifestyles. Accordingly, it is essential that the undergraduate kinesiology core explore in detail the relationship between physical activity participation, health, and well-being.

\section{Scientific Foundations of Physical Activity}

A defining feature of the academic discipline of kinesiology is its embrace and integration of the multidimensional study and application of physical activity. Well-prepared kinesiologists are expected to have a sound understanding of the scientific foundations of physical activity. For many departments, this scientific foundation is provided by a series of courses that are taken by all majors regardless of their ultimate career goals. Examples of scientific foundation courses include exercise physiology (Ivy, 2007), motor behavior (Fischman, 2007; Ulrich, 2007), biomechanics (Hamill, 2007), and exercise and sport psychology (McCullagh \& Wilson, 2007). These specific titles and content of scientific foundation courses offered in degree programs will vary from one institution to another depending on the local (faculty and college) preferences, career alignment with degree programs, and resources (faculty expertise and teaching loads, laboratory facilities and equipment, etc.) available.

\section{Cultural, Historical, and Philosophical Dimensions of Physical Activity}

A solid grounding in cultural, historical, and philosophical aspects of kinesiology is an essential component of a kinesiology education. For both individuals and communities, sociocultural and historical factors influence attitudes about and practices of physical activity. Duncan (2007) provides an illustrative examination of how sociology of sport contributes to broader understandings in kinesiology. In addition, an understanding of philosophical and historical issues will help prepare the future professionals for the numerous ethical questions they will face on graduation. Coursework in the humanities helps students understand and appreciate diversity, develop cultural competencies, and make ethical decisions based on sound principles. In many kinesiology departments, undergraduate coursework examines topics related to physical culture, cultural kinesiology, sociology of sport and physical activity, and history of sport and physical activity. As with the other core elements, how the content is presented in kinesiology courses may vary from institution to institution.

Moreover, for every area of study and every career option, there are significant historical people and events that shape those areas and careers. Professionals must have a deep understanding and appreciation for the history of their chosen career. This historical information may be included in the discipline-specific courses (i.e., exercise physiology, motor behavior, or biomechanics of sport) or in a separate historical perspective of our discipline.

\section{The Practice of Physical Activity}

Regular participation in physical activity is an essential component of a healthy and successful lifestyle, and the undergraduate curriculum should provide numerous opportunities for students to be physically active. While the AKA strongly supports students' being physically active, it does not prescribe specific activities or processes for departments to follow regarding how the practice of physical activity is incorporated into the curriculum but staunchly supports curricular or extracurricular physical activity experiences for individual and group participation.

The AKA also considered alternative meanings that could be applied to the "practice of physical activity." Those who organize sports events or physical activity programs for youth or adults are engaged in the practice of physical activity. Although regular physical activity is important for the individual, one who organizes and promotes physical activity for others is also engaged in the practice of physical activity. Knowledge about how to implement healthy and safe programs for different groups is critically important (Rink, 2007; Silverman, 2007). In this regard, the practice of physical activity requires one to apply the information gained from the other three core content areas to deliver the appropriate physical activities for other participants, whether they be elite athletes, elderly individuals, adults and children, or individuals with special needs.

\section{Assessment of Student Learning Outcomes for the Kinesiology Core}

Academic degree programs are now required to declare what their students are expected to learn in the programs and the extent to 
which those students achieved the expected learning outcomes (Reeve, 2010). Although a primary emphasis for assessing learning outcomes comes from institutional accreditation requirements, current requirements, for the most part, allow faculty within the disciplines to define the learning outcomes, to specify the methods of assessment, and to analyze and evaluate the specific outcomes. Zhu (2007) provided a detailed discussion of the procedures and considerations for assessment of learning outcomes in kinesiology. The intent of assessment is to ensure that students are learning the critical content in their chosen discipline and to use results of the assessments to improve the learning experiences for the students.

Assessment of student learning is focused on outcomes at the program or degree level and not at the individual course level. Because the kinesiology core represents the foundational knowledge for the discipline, it should be expected that all kinesiology students will have foundational knowledge relevant to each of the core areas. Moreover, the students should have extensive knowledge in one or more of the core content areas that represent their specific areas of study within kinesiology. In this way, concentrations within a degree program or in separate degree programs in kinesiology might specify different levels of knowledge for each of the core content areas. In all cases, however, learning opportunities from all four content areas, regardless of how those experiences are presented, are evident within each concentration or program.

For each of the AKA undergraduate core curricular elements it is important to identify clearly stated learning outcomes. A sample set of learning outcomes that are consistent with the AKA core elements was developed by an AKA working group. These learning outcomes are intended to serve as exemplars of possible learning outcomes. Individual departments are free to adopt these outcomes, modify them, or develop their own.

\section{Kinesiology Core Elements}

\section{Physical Activity in Health, Wellness, and Quality of Life}

A kinesiology graduate will be able to

1. Describe the relationship between physical activity participation and health, wellness, and quality of live, including a detailed explanation of current physical activity guidelines and recommendations.

2. Critically evaluate research related to physical activity and its impact on health and chronic disease.

3. Design and evaluate physical activity programs that promote health and improve quality of life.

\section{Scientific Foundations of Physical Activity}

A kinesiology graduate will be able to

4. Explain how the scientific process informs our understanding of physical activity.

5. Describe the underlying scientific foundations of physical activity.

6. Critically evaluate information about physical activity from a scientific basis.

\section{Cultural, Historical, and Philosophical Dimensions of Physical Activity}

A kinesiology graduate will be able to
7. Describe the sociocultural and historical factors that influence physical activity.

8. Demonstrate an appreciation of cultural diversity and make ethical decisions.

9. Critically evaluate scholarly work related to cultural, historical, and philosophical dimensions of physical activity.

\section{The Practice of Physical Activity}

A kinesiology graduate will be able to

10. Describe indicators of an individual's regular participation in physical activity.

11. Demonstrate an appreciation of and commitment to physical activity practice.

12. Evaluate the quality of her or his own practice of physical activity.

\section{Assessment Procedures and the Core Content}

For the listed learning outcomes, several points need to be emphasized. First, these statements may be more generic that what an actual program would use. That is, what the student is expected to know and do may be stated in more specific terms depending on the purpose of the program.

Second, these examples of learning outcomes within each core element are hierarchical in that each stated outcome generally requires or builds on the preceding one (see Anderson \& Krathwohl, 2001, for discussion of a taxonomy educational objectives). For example, to be able to evaluate, one must be able to describe or define a concept. For this reason, only one learning outcome would be needed in most cases to address the core content for kinesiology. The faculty in a department would determine the appropriate level of knowledge for an outcome that is specific to the concentration or degree program, but additional and more advanced outcomes should be stated to satisfy the expected outcomes for the higher-level knowledge required for a specific area of study within kinesiology.

Third, the specific methods of assessment for each learning outcome have not been stated in these examples. How will the data be collected, analyzed, and evaluated to determine the extent to which students in the program have achieved the desired learning outcomes?

Finally, it is the responsibility of program faculty to determine the specific learning outcomes for their programs. The faculty will also decide when and how to collect the appropriate data for each learning outcome and then analyze and interpret the results. The final decisions about whether program changes are necessary to improve students' performances on the learning assessments are also the responsibility of the faculty.

A wide variety of approaches exist to assessing student learning in academic programs. These approaches may draw on the students' actual performance in courses, on standardized tests, or on observed behaviors in real-word situations. Alternatively, the approaches by be based on students' perceptions of their learning, observations from others (i.e., employers), or other "supporting" sources of information related to the students' learning.

Table 1 provides a method to conceptualize these different approaches to assessment. The purpose of the table is to help one think about where assessment information will come from and what type of information it represents. Assessment approaches can be categorized as direct (based on the students' performances 
Table 1 A Method for Conceptualizing Approaches to Outcomes Assessment

\begin{tabular}{|c|c|c|}
\hline & Direct & Indirect \\
\hline $\begin{array}{l}\text { Internal } \\
\text { assessment }\end{array}$ & $\begin{array}{l}\text { - Students' performances on selected assignments in or across } \\
\text { courses } \\
\text { - Students' performances in capstone courses (internships, } \\
\text { - Jenior seminars) } \\
\text { - Suried reviews of senior projects } \\
\text { - Renior exams covering the major topics of the major } \\
\text { defenses }\end{array}$ & $\begin{array}{l}\text { - Results of focus-group meetings with students } \\
\text { - Students' evaluation of the program } \\
\text { - Individual students' exit interviews (use random sampling of } \\
\text { students) } \\
\text { - Graduate follow-up studies }\end{array}$ \\
\hline $\begin{array}{l}\text { External } \\
\text { assessment }\end{array}$ & $\begin{array}{l}\text { - Performances on certification or licensure examinations } \\
\text { - Former students' performances on the job } \\
\text { - Acceptance rates into graduate schools and professional } \\
\text { programs } \\
\text { - Externally reviewed exhibits and performances in the arts }\end{array}$ & $\begin{array}{l}\text { - Employers' perceptions of former students' knowledge and } \\
\text { competencies } \\
\text { - Job placement data } \\
\text { - Industry opinions of competence of graduates in major }\end{array}$ \\
\hline
\end{tabular}

related to the expected learning outcomes) or indirect. These approaches can also be internal (information gathered from the program's requirements) or external. Obviously, the most accurate assessments of students' learning would be the direct measures, and the most efficient method to gather this information would be to use an internal (within the program) approach (Eder, 2001).

As noted, this conceptualization is designed to help one think about what the different sources are for assessing student learning. As different methods of assessment are identified it is not necessary to "place" each in a specific category (some overlaps between categories may exist); rather, what is important is to think about what information may be available from assessment approaches that already exist in a program.

Table 2 indicates the relationship between student evaluations (grading) and using a direct/internal assessment for assessment of a program learning outcome. In this example, each faculty member teaching a section of KIN 451 (a hypothetical undergraduate course) includes the instructor's requirements for the course and the agreed-upon requirement for the individual project. Rubrics should be written to describe the levels of performance for grading the individual project (Anderson \& Krathwohl, 2001). The final grades are determined by totaling the scores from each student's performances on tests, homework, and the individual project. Program outcomes assessment is accomplished by calculating the percentage of students who are able to achieve a predetermined level of performance on the individual project. This approach allows the faculty to create their own assignments (tests, homework, etc.) for the course and also to include an embedded program outcome assessment in the course. The program outcome not only ties the course content to the program's purpose but also allows for a direct/internal assessment of the students' learning.

In many cases, these types of assignments already exist. The program assessment is accomplished by analyzing the students' performances on the expected outcomes in the aggregate. Obviously, the example in Table 2 is hypothetical and as such is stated in simplistic terms. Once faculty members begin to develop their program outcomes assessments, more explicit criteria and methods of assessment will develop.

\section{Examples of the Core in Kinesiology Curricula}

The AKA asked member departments to provide examples of how their undergraduate curricula incorporate the kinesiology core content. From the submitted curricula, the AKA selected one curriculum model from each of the following classifications of institutions: doctoral-degree-granting institutions, master's-degree-granting institutions, and bachelor's-degree-granting institutions. These curriculum materials can be reviewed on the AKA's website: http://www. americankinesiology.org/SubPages/Pages/Learning\%20Outcomes.

Examination of these three examples reveals that these programs offer one or more courses for each of the core content areas. This suggests that more than an introductory level of knowledge is expected in each of these core areas. In addition, the scientific foundations of physical activity core content include the largest number of required courses in each curriculum. Kinesiology is a science-based discipline with close alignment to numerous basic sciences such as biology, anatomy and physiology, and psychology, among others. Typically, undergraduate students are expected to have the highest level of knowledge in the science of physical activity. These comments are based on a limited review, but consistency across the programs demonstrates a common acceptance of the significance of a scientific understanding of physical activity. A more extensive investigation of kinesiology curricula is recommended to better understand how academic departments organize kinesiology core content.

Obviously, there are other institutions that will deviate from these generalizations. To the extent that these programs have developed a well-defined purpose with clear learning outcomes, these variations are a strength of kinesiology. That is, kinesiology is a broad-based discipline, and the study of physical activity requires different curriculum models to accommodate the numerous career opportunities associated with our discipline.

\section{Using the Core Content to Implement a Bachelor's Degree in Kinesiology: A Case Study From Delaware State University}

This case study outlines how the Department of Public and Allied Health Sciences at Delaware State University (DSU) used the AKA core and its Strategic Planning and Assessment Support Program to complete a major curriculum revision (http://americankinesiology. org/).

The Fitness Promotions major at DSU was formed in 2006. The name changed to Movement Science in 2008, and the department of Public and Allied Health Sciences was formed in 2009. The Movement Science major had two concentrations, Pre-Health 


\section{Table 2 Hypothetical and Simplified Example (Kin 451) of Student Evaluations (Grading) and a Direct/Internal (Embedded) Approach to Program Assessment}

\begin{tabular}{|c|c|c|c|c|c|c|c|}
\hline \multirow[b]{2}{*}{ Student names } & \multicolumn{5}{|c|}{ Scores } & \multirow[b]{2}{*}{$\begin{array}{l}\text { Total } \\
\text { points }\end{array}$} & \multirow[b]{2}{*}{$\begin{array}{l}\text { Final } \\
\text { grade }\end{array}$} \\
\hline & $\begin{array}{c}\text { Test } \\
1\end{array}$ & $\begin{array}{c}\text { Test } \\
2\end{array}$ & $\begin{array}{l}\text { Final } \\
\text { exam }\end{array}$ & $\begin{array}{c}\text { Total of } 5 \text { homework } \\
\text { assignments }\end{array}$ & $\begin{array}{c}\text { Individual } \\
\text { project }\end{array}$ & & \\
\hline John & 75 & 82 & 72 & 80 & 78 & 387 & $\mathrm{C}$ \\
\hline Mary & 89 & 92 & 87 & 94 & 92 & 454 & $\mathrm{~A}$ \\
\hline Billy & 77 & 77 & 85 & 81 & 83 & 403 & $\mathrm{~B}$ \\
\hline \multicolumn{8}{|c|}{$\begin{array}{l}\text { Continue listing students, scores, and } \\
\text { final grades }\end{array}$} \\
\hline \multicolumn{7}{|c|}{ Calculate percentage of students scoring 80 points or higher on individual project (based on use of rubric to score student performances). } & $\%$ \\
\hline \multicolumn{7}{|c|}{$\begin{array}{l}\text { Assessment: Did } 85 \% \text { or more of the students score } 80 \text { points or higher? If "yes," criterion level of performance is achieved for the program } \\
\text { on this outcome. If "no," improvements are necessary in this course or supporting courses to enable students to achieve desired level of } \\
\text { performance. Make and document necessary program improvements. }\end{array}$} & Yes/No \\
\hline
\end{tabular}

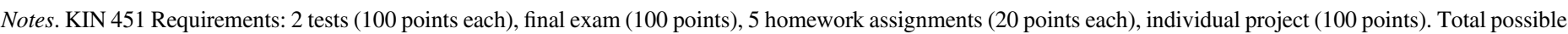
points for course: 500 . Final grade: $\mathrm{A}=500-450$ points, $\mathrm{B}=449-400, \mathrm{C}=399-350, \mathrm{D}=349-300, \mathrm{~F}<300$.

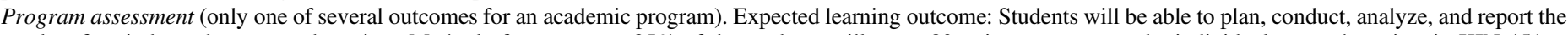

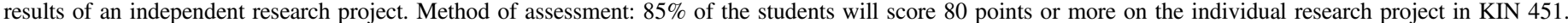

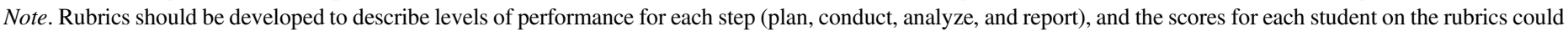
be used in the method of assessment. Faculty would develop the rubrics to be used in grading the individual projects.

Professional and Health/Fitness Certification. Movement Science curricula were revised in 2011 and again in 2015. Curriculum revision is a necessary part of maintaining any program. However, as the Movement Science program had undergone numerous revisions since it was initially adopted, there was scrutiny from administration over the decision to revise within a year after the 2015 curricula had been approved. Additionally, there was disagreement among faculty on the need to revise the curricula. Most of the concern was over the lack of strong program assessment data to support the revision. Unfortunately, the department did not develop a transition plan for students to change from one curriculum to the next. Decisions were not consistently made regarding course equivalencies between curricula and for course substitutions. Anecdotally, faculty saw a need for revision, and it did not seem practical to wait until the program was delivered as designed to get meaningful assessment data.

An additional concern was the alignment of courses with the knowledge, skills, abilities, and competencies identified by the American College of Sports Medicine (ACSM) and National Strength and Conditioning Association (NSCA). There was specific coursework that supported ACSM and NSCA certification. There were concerns that the AKA core content would not support the program connections with ACSM and NSCA, especially as the program was designated as an NSCA Education Recognition Program. This concern was alleviated once the department faculty became more familiar with the AKA and realized that these professional organizations are complementary and not competitive.

In the past, the "Band-Aid" approach had been taken with curriculum changes. The noted problem areas of the curriculum were addressed, and changes were made to improve those areas. While the goal was always to have a program consistent with the university's goals to prepare students to be competitive for employment and graduate programs, it was noted that a new approach to curriculum revision was needed. The goal shifted from fixing problems to building a program with the 2017 revision.

When the curriculum committee members reviewed the AKA core documents and contacted the AKA consultant, it was evident that the core would be instrumental in developing a new curriculum. The first step in the process was a review of the current curricula and faculty expertise. The curriculum committee received a very thorough, objective assessment of the Movement Science concentrations. This feedback provided necessary support for the revision and was key in getting support from the college administration to move forward with the revision. Although not all faculty were fully supportive of the revision, they were receptive to the process of getting external guidance from a credentialed consultant.

One of the most appealing and beneficial features of the AKA core is that it provides a framework for the program that guides curriculum development by identifying the elements that should be included in any kinesiology curriculum, yet it allows flexibility for the specific needs and goals of the individual program to be met. The DSU kinesiology curriculum was built on the foundation of the AKA core, and it aligns with the university's core values and supports its key performance indicators, college goals, departmental goals, and faculty expertise.

The first major change was the name of the major itself. The Movement Science major became Kinesiology, a more recognizable name than Movement Science. The name change improves the marketability of the major for incoming students. In addition, it will be more recognizable than Movement Science for students applying to graduate programs and entering the workforce. The report from the AKA consultant stated that "over the past 10 years there has been a growing consensus that Kinesiology is the appropriate name for the academic discipline and that other names better represented fields of studies within the discipline of Kinesiology."

Approximately $75 \%$ of Movement Science majors had selected the Pre-Health Professional concentration that was designed to prepare students for the physical therapy, occupational therapy, and athletic training programs, as well as graduate programs in exercise science and other kinesiology-related areas of study. The remaining $25 \%$ of Movement Science students were enrolled in the Health and Exercise Science concentration. The intention of this concentration was to prepare students to enter the workforce on graduation. However, it was noted that many of the students in the Health and Exercise Science concentration planned to attend graduate or professional school, and the elective courses chosen by students in the Health and Exercise Science concentration were frequently required courses from the Pre-Health 
Professional curriculum. Significant overlap was noted between the two concentrations, especially when the elective choices were considered. The second major change with the 2017 revision was to collapse the concentrations into one kinesiology major.

This change reduced the number of required courses that must be offered every semester. Class enrollment caps were decreased for classes, and more elective course offerings were made available on a regular rotation. Additionally, this change decreased the number of class preparations for faculty to manage with their teaching loads. The consultant commented that

The high degree of overlap suggests that the two concentrations are not distinctive degree options. But relying on different curricula concentrations has the potential to create a lack of efficiencies in program delivery and cause some confusion among students as to the intended differences in the concentrations.

These comments supported the decision to collapse the concentrations into one program. Additionally, courses (e.g., nutrition, anatomy, and physiology) that students would now take in other departments were no longer offered by kinesiology faculty, which also allowed faculty to focus on areas of content expertise and further improve efficiency of program delivery.

The proposed kinesiology curriculum map based on feedback and recommendations was sent to the AKA consultant for review after the initial changes were made. Minor adjustments were made at this point, and the next step was to rewrite the student learning outcomes (SLOs) and revise the individual courses. The committee then worked with the consultant to improve the presentation of the SLOs and program goals. The new SLOs were revised based on the AKA core and also incorporated the DSU core values, showing how students are being prepared in a way that supports the university's values. In addition, prospective employers and graduate program faculty will know that DSU students have been exposed to the recommended breadth of the discipline.

Courses were then modified to align with the new SLOs and program goals. One specific change that is expected to affect positive placement for kinesiology majors at DSU is the addition of laboratory components to three courses, as well as other experiential learning opportunities in the required coursework. These changes will provide additional hands-on experiences for the students. These experiences will provide students with skills that will better prepare them for internships, graduate programs, and the job market. In addition, these changes increase the number of paid and volunteer laboratory assistants needed. All of the changes support the DSU strategic plan and key performance indicators for experiential learning and positive placement.

After this step, the new kinesiology curriculum was ready for review and approval by the department faculty. Overall, the proposed curriculum was well received by the faculty and there was a general appreciation for use of the consultation service because it made the process more objective and reduced possible personal and professional biases of faculty in the department. The college administration also appreciated the objective approach and the improvement in faculty buy-in. Approval at the college and faculty senate level was unanimous. There were numerous positive comments from within and outside the college on the approach that was taken and the improvements in program.

After approval at all levels, a transition plan was put into place and meetings were held to inform students of the changes and how the changes would affect them. Current students were informed of how they could complete the current Movement Science program and how courses would be offered in a way that would not affect graduation. In addition, they were informed which courses were required if they chose to change to the new kinesiology major. Students had a positive response to the program changes. The most negative response was from students who were too far into the Movement Science program, because they students could not change to the new curriculum. The transition has been smooth, with the biggest challenge being misinformation about the transition plan. It was apparent that both students and faculty need accurate and timely information throughout the transition period. The next step in the process is to continue working with the consultant to develop the final assessment plan for the kinesiology curriculum.

The use of the consultant service and the AKA core was instrumental in developing a strong new kinesiology curriculum for the Department or Public and Allied Health Sciences at Delaware State University. The key benefits for this department include

- A solid framework that allowed flexibility for program development

- Objective feedback and assistance from a credentialed expert

- Increased faculty agreement and buy-in on the need to revise and the revisions

- Unanimous support from the college and university faculty and administration

- The opportunity for continued work with the consultant for assessment and strategic planning

- The development of a strong program for students that also improves the efficiency of program delivery

\section{Concluding Observation}

The AKA promotes kinesiology as a unified field of study focused on physical activity. As an academic discipline, kinesiology undergraduate degree programs must include a core of knowledge and skills that all graduates in the discipline have in common. Because of the breadth of content in kinesiology and the extensive range of career opportunities, one should not expect that graduates of kinesiology programs have the same experiences or exposure to all discipline content. What is important is that undergraduate students learn the fundamental content of the discipline (i.e., the core) and then develop the in-depth knowledge and skills essential to their specific degree program and career interests in kinesiology. Establishing the appropriate curriculum and student learning outcomes for each of the four core elements consistent with a degree program's purpose enables the program to prepare students as kinesiologists who are specifically educated to contribute differently in the field of physical activity.

\section{Acknowledgment}

The American Kinesiology Association (AKA) Core Curriculum is considered to be in the public domain, and the AKA reserves the right to reproduce the core curriculum materials in a number of formats.

The Delaware State University curriculum revision could not have been completed without the hard work of the committee dedicated to developing a strong curriculum. Ms. Patrice Elder worked closely with Dr. Reeve to apply the AKA to the DSU program. Drs. R. Chris Mason, Sangeeta Gupta, and Knolan Rawlins were also instrumental in the development and implementation of the new curriculum. 


\section{References}

Ainsworth, B.E., \& Hooker, S.P. (2015). The fusion of public health into kinesiology. Kinesiology Review, 4, 322-328. doi:10.1123/kr.20150032

Anderson, L.W., \& Krathwohl, D.R. (Eds.). (2001). A taxonomy for learning, teaching, and assessing: A revision of Bloom's taxonomy of educational objectives (complete ed.). New York, NY: Longman.

Chodzko-Zajko, W. (2014). The American Kinesiology Association undergraduate core curriculum. Quest, 66, 288-294. doi:10.1080/ 00336297.2014 .918896

Christina, R.W. (2009). Re-examining the undergraduate core in kinesiology in a time of change. Retrieved from http://americankinesiology. org/Content/Documents/Re-Examining\%20the\%20Undergraduate \% 20Core $\% 20$ in $\% 20$ Kinesiology $\% 20$ in $\% 20$ a\%20Time $\% 20$ of\%20Change \%20-Christina.pdf

Duncan, M.C. (2007). Bodies in motion: The sociology of physical activity. Quest, 59, 55-66. doi:10.1080/00336297.2007.10483536

Eder, D.J. (2001). Accredited programs and authentic assessment. In C.A. Palomba \& T.W. Banta (Eds.), Assessing student competence in accredited programs: Pioneering approaches to assessment in higher education (pp. 199-216). Sterling, VA: Stylus Publishing.

Fischman, M.G. (2007). Motor learning and control foundations in kinesiology: Defining the academic core. Quest, 59, 67-76. doi:10. 1080/00336297.2007.10483537

Hamill, J. (2007). Biomechanics curriculum: Its content and relevance to movement science. Quest, 59, 25-33. doi:10.1080/00336297.2007. 10483533

Ivy, J.L. (2007). Exercise physiology: A brief history and recommendations regarding content requirements for the kinesiology major. Quest, 59, 34-41. doi:10.1080/00336297.2007.10483534

Johnson, T.G., \& Twietmeyer, G. (2018). The necessity of physical activity in kinesiology degree programs. Journal of Physical Education, Recreation \& Dance, 89(2), 42-48. doi:10.1080/07303084. 2017.1404513
Lawson, H. (2010). The American Kinesiology Association and the future of kinesiology. Kinesiology Today, 3(1). Retrieved from http:// americankinesiology.org/Content/Documents/KT_Winter_2010_Vol-3_ No-1.pdf

McCullagh, P., \& Wilson, G. (2007). Psychology of physical activity: What should students know? Quest, 59, 42-54. doi:10.1080/ 00336297.2007.10483535

Morrow, J.R., Jr., \& Thomas, J.R. (2010). American Kinesiology Association: A national effort to promote kinesiology. Quest, 62, 106-110. doi:10.1080/00336297.2010.10483635

Newell, K.M. (2007). Challenges of multiple agendas. Quest, 59, 5-24. doi:10.1080/00336297.2007.10483532

Reeve, T.G. (2007). Kinesiology: Defining the academic core of our kinesiology: Introduction. Quest, 59, 1-4. doi:10.1080/00336297. 2007.10483531

Reeve, T.G. (2010). Assessment, accreditation, and accountability: Using the a-list to promote kinesiology programs in higher education. Quest, 62, 15-34. doi:10.1080/00336297.2010.10483630

Rink, J. (2007). What knowledge is of most worth? Perspectives on kinesiology from pedagogy. Quest, 59, 100-110. doi:10.1080/ 00336297.2007.10483540

Silverman, S. (2007). Mingling with our friends: The kinesiology student and pedagogy knowledge. Quest, 59, 92-99. doi:10.1080/00336297. 2007.10483539

Templin, T.J., \& Blankenship, B.T. (2007). Accreditation in kinesiology: The process, criticism and controversy, and the future. Quest, 59, 143-153. doi:10.1080/00336297.2007.10483543

Twietmeyer, G. (2018). Hope \& kinesiology: The hopelessness of healthcentered kinesiology. Sport, Ethics and Philosophy, 12(1), 4-19. doi:10.1080/17511321.2017.1291712

Ulrich, B. (2007). Motor development: Core curricular concepts. Quest, 59, 77-91. doi:10.1080/00336297.2007.10483538

Zhu, W. (2007). Assessing kinesiology students' learning in higher education. Quest, 59, 124-142. doi:10.1080/00336297.2007.10483542 